\title{
Photoacoustic Thermal Characterization of Banana Fibers
}

\author{
Foluke Salgado Assis ${ }^{a}$, Frederico Muylaert Margem ${ }^{a}$, Thallis Custódia Cordeiro ${ }^{a}$, \\ André Ben-Hur Figueiredo ${ }^{b}$, Fabio Oliveira Braga ${ }^{b}$, Sergio Neves Monteiro ${ }^{b}$ * \\ ${ }^{a}$ Advanced Materials Laboratory, Universidade Estadual do Norte Fluminense - UENF, \\ Av. Alberto Lamego, 2000, CEP 28013-602, Campos dos Goytacazes, RJ, Brazil \\ ${ }^{b}$ Department of Materials Science, Instituto Militar de Engenharia - IME, Praça General Tibúrcio, 80, \\ Praia Vermelha, Urca, CEP 22290-270, Rio de Janeiro, RJ, Brazil
}

Received: December 14, 2014; Revised: November 23, 2015

\begin{abstract}
Natural fibers are attracting the interest of engineering sectors owing to specific advantages such as lightweight and lower cost as well as an inherent condition of being renewable, biodegradable, recyclable and environmentally correct with respect to $\mathrm{CO}_{2}$ emission. In addition, several natural fibers present mechanical and thermal properties appropriate for engineering applications. The fiber extracted from the stem of the banana plant is nowadays recognized by its mechanical properties. However, some thermal properties of the banana fibers have not yet been fully investigated. The present work investigated, by photoacoustic spectroscopy and photothermal techniques, the thermal diffusivity, specific heat capacity and thermal conductivity of the banana fiber. The results revealed that the banana fibers showed a promising thermal insulation capacity, comparable to those of conventional synthetic insulators.
\end{abstract}

Keywords: photoacoustic technique, banana fiber, thermal properties

\section{Introduction}

Synthetic fiber reinforced composites have been, since the beginning of the last century, one of the fast growing group of materials with engineered combination of properties, which cannot be achieved by a conventional material ${ }^{1,2}$. This is particularly the case of systems and components demanding superior performance in medical, sports, aerospace and automobile applications ${ }^{3,4}$. For instance, modern aircrafts demand lighter, stronger, tougher and stiffer structural parts that can only be made with carbon fiber reinforced pyrolized graphite matrix composites. Common and less expensive, glass fiber composites are also used as interior components of aircrafts in addition to an extensive application in many other products, from packaging to automobile components ${ }^{4}$. All synthetic composites like the aforementioned ones reinforced with carbon and glass fibers are, however, associated with environmental drawbacks. Their production is energy-intensive and they cannot be easily recycled. Glass fiber, in particular, is related to respiratory health problems ${ }^{5}$. Since recent years, natural fibers are being considered a convenient substitute for glass fiber in engineering composites ${ }^{6,7}$. Actually, natural fibers have already replaced the common glass fiber E, as the reinforced phase of polymeric composites in many engineering applications such as automobile interior components ${ }^{8-10}$, cyclist helmets, housing panels and windmill fins ${ }^{11}$. The natural lignocellulosic fibers obtained from vegetables offer societal, economical, environmental and technical benefits ${ }^{12}$. The main technical advantages of their composites are the low density and less wear to process equipments, especially by using natural

*e-mail: snevesmonteiro@gmail.com fibers as reinforcement to suit the mechanical performance requirements ${ }^{13-20}$.

A less known lignocellulosic fiber, which is gaining attention as a potential reinforcement for engineering composites is the banana fibers ${ }^{21}$. Banana is worldwide known and a favorite fruit in many countries, comprising several species of the musacea family. India, Ecuador, Brazil and Central America are the largest producers and exporters of the banana fruit. The banana plant, illustrated in Figure 1a, with pseudo-stem (stem, for short) up to $9 \mathrm{~m}$ long and $0.4 \mathrm{~m}$ in diameter, produces just one bunch. For this reason, after harvest, the stem is cut, Figure $1 \mathrm{~b}$ to allow new sprouts to grow for the production of another bunch of bananas. As a normal procedure, the old stem is thrown on the ground and used for mulching. A more profitable and technically feasible alternative for the discarded banana stem, Figure 1b, is to extract fibers, either manually or using a decorticator, for possible engineering uses including reinforcement of polymer composites ${ }^{21}$.

In fact, the banana fiber was reported to reach a tensile strength of $800 \mathrm{MPa}$ as well as an elastic modulus of $32 \mathrm{GPa}$ and total elongation of $3.7 \% \%^{21}$. These mechanical properties, together with a lower density of $0.67-1.50 \mathrm{~g} / \mathrm{cm}^{3}$, are comparable to those found for common lignocellulosic fibers already applied as engineering materials for composites reinforcement ${ }^{21}$. Actually, polymer composites reinforced with banana fibers are current being considered for automobile components, as illustrated in Figure 2.

In recent years, several research works have investigated the technical characteristics and mechanical properties 


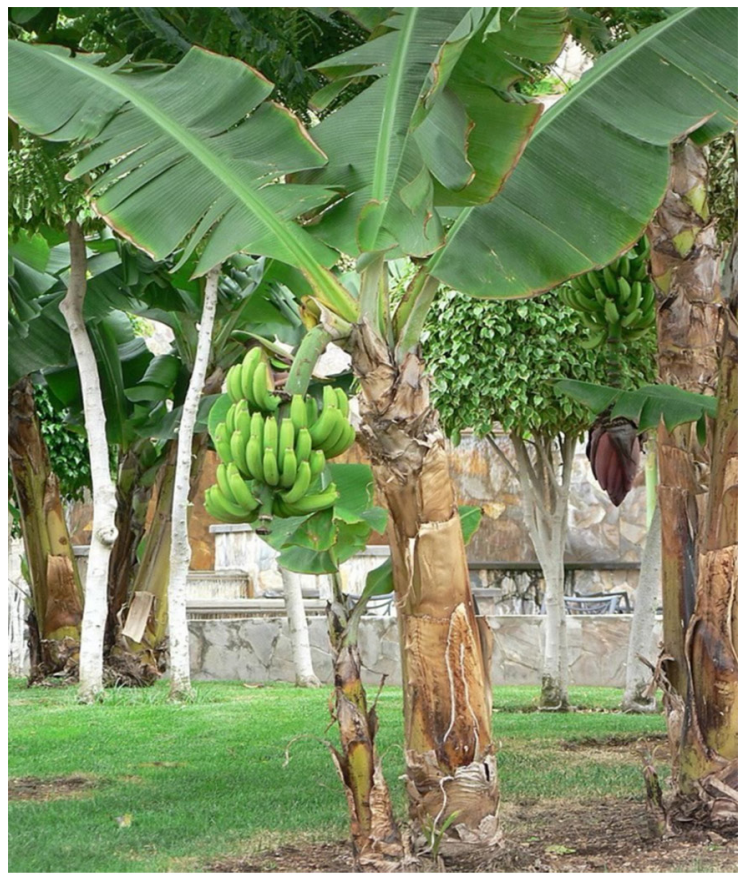

(a)

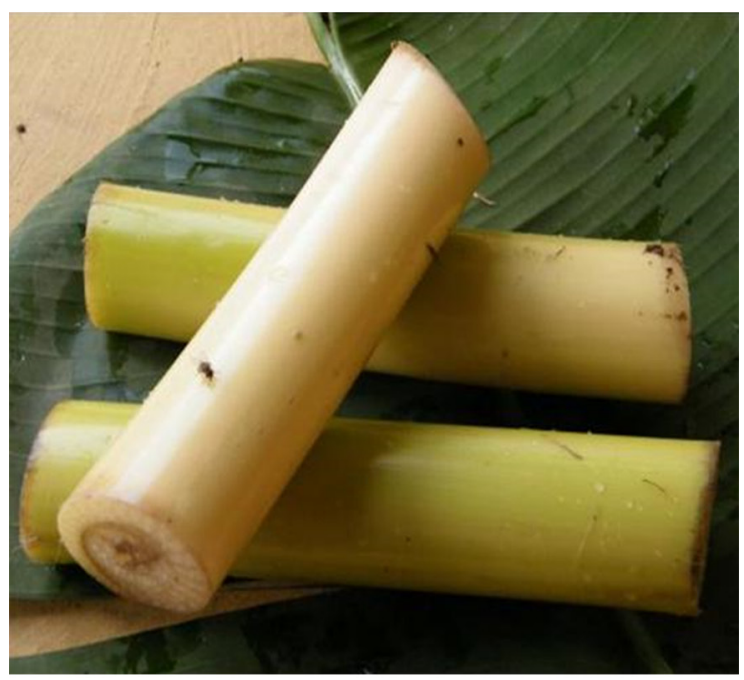

(b)

Figure 1. Banana plant (a) and stem cut after harvest (b).

of the banana fiber and related composites ${ }^{22-33}$. Some of these works ${ }^{22,23,27-29}$ reported on thermal properties such as TG/DTG, DSC, and DMA. However, other thermal properties like the specific heat capacity, thermal diffusivity and thermal conductivity were not evaluated. These properties can be precisely determined by photoacoustic spectroscopy combined with photothermal techniques that are well established to characterize insulating materials ${ }^{34}$. These techniques are based on heat generation as a result of radiation absorption ${ }^{35-37}$ and were applied to polymeric materials ${ }^{35}$. Based on these assumptions, the present work carried out a preliminary photoacoustic and photothermal characterization of banana fiber.

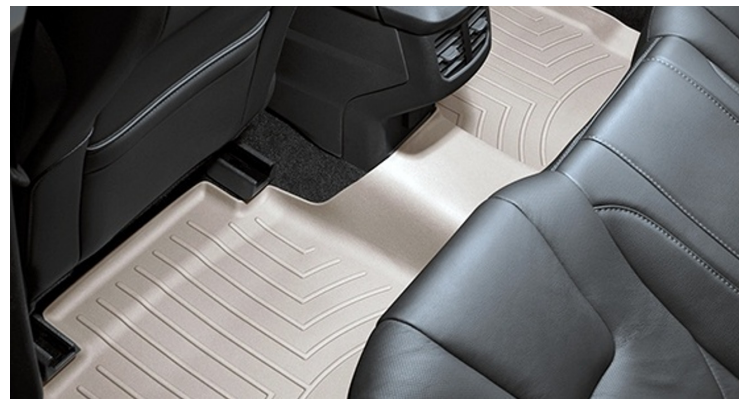

Figure 2. Car mat of the Ford Lincoln made of banana fiber composite.

\section{Experimental Procedure}

Fibers extracted from splints, Figure 3a, cut out of the stem of the banana plant of the scientific family Musa balbisiana, were supplied as a bundle, Figure 3b, by a group of artisans based in the State University Northern Rio de Janeiro, located in the city of Campos dos Goytacazes, Brazil. The as-supplied banana fibers were cleaned with water and dried in a stove for one hour at $60^{\circ} \mathrm{C}$. No further treatment was applied to the fibers to avoid additional processing costs.

The photoacoustic analysis sample preparation consist in a painstaking process, in which pieces are manually removed from one splint, Figure $3 \mathrm{a}$, which was then polished to a thickness of approximately $0.5 \mathrm{~mm}$, as seen in Figure $4 \mathrm{a}$. Each one of these sample pieces was tested in an open cell using photoacoustic and photothermal techniques, schematically shown in Figure 4b. The photothermal method under normal continuous incidence of laser illumination was applied for light interaction with the sample. Both the photoacoustic and the photothermal techniques were used to determine the thermal diffusivity $\alpha_{s}$, and the specific heat capacity $\rho c_{p}$ ( $\rho$ is the density and $\mathbf{c}_{\mathbf{p}}$ is the heat capacity at constant pressure). From these parameters, the thermal conductivity of banana fiber $(\mathrm{k})$ was evaluated by the equation:

$$
\mathrm{k}=\alpha_{\mathrm{s}} \rho \mathrm{c}_{\mathrm{p}}
$$

The thermal diffusivity was measured by the photoacoustic technique, which considers heat loss in a sample due to a thermal relaxation process after light absorption. The open photoacoustic cell (OPC) $)^{37}$ has as its main purpose to assemble a sample, Figure $4 b$, directly into a cylindrical microphone. The air chamber of the front of microphone works as a conventional gas chamber, usually applied in others photoacoustic techniques ${ }^{36}$. The results interpretation is based on the fact that, during the OPC operation, the thermoelastic mechanism is dominant. The value of $\alpha_{s}$ was then obtained by fitting of experimental phase data, $\phi$ by the equations ${ }^{16}$ :

$$
\begin{aligned}
& \varphi=\varphi_{\mathrm{o}}+\arctan \left(\frac{1}{\mathrm{x}-1}\right) \\
& \mathrm{x}=\ell_{\mathrm{s}}\left(\frac{\pi \mathrm{f}}{\alpha_{\mathrm{s}}}\right)^{1 / 2}
\end{aligned}
$$

where $\boldsymbol{\ell}_{\mathrm{s}}$ is the sample thickness and $\mathbf{f}$ the photoacoustic signal frequency. It is assumed that the sample is optically opaque, and the heat flow in the surrounding air is negligible. 


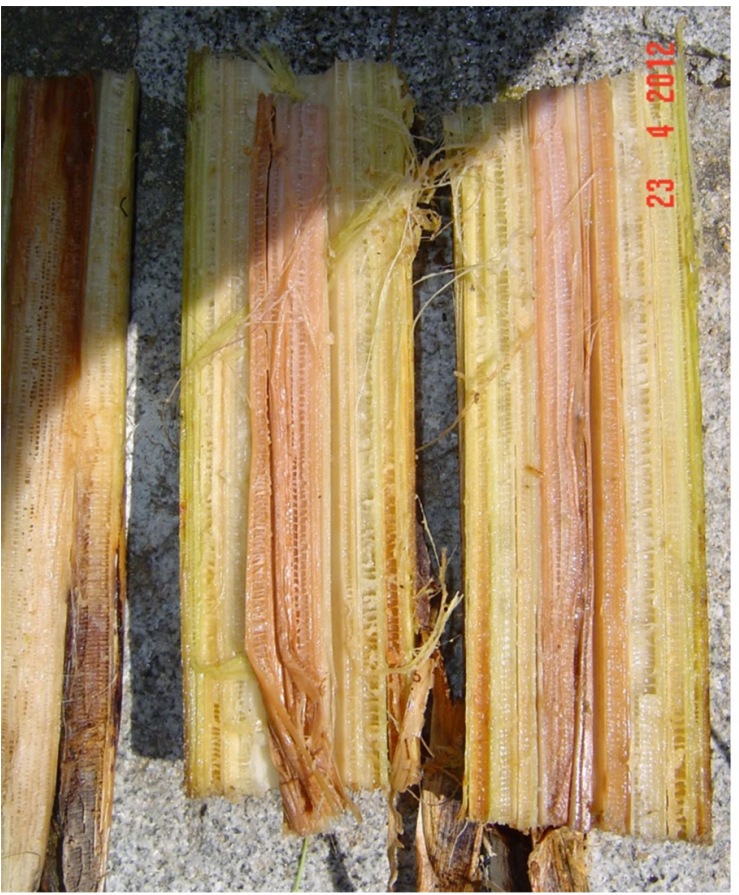

(a)

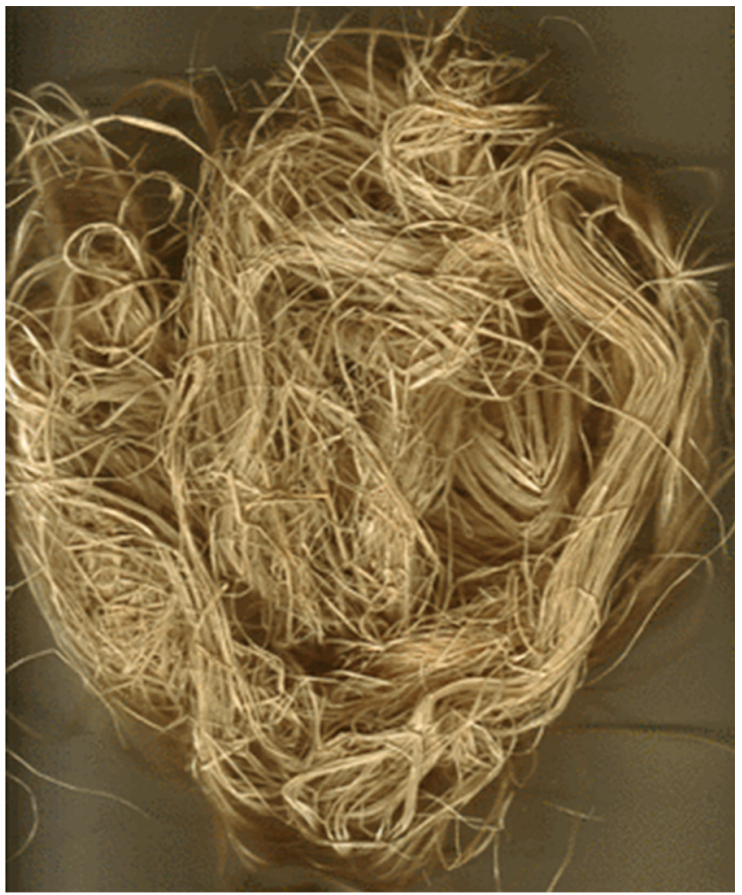

(b)

Figure 3. Banana (a) splints cut out of the stem and (b) bundle of fibers extracted from the splints.

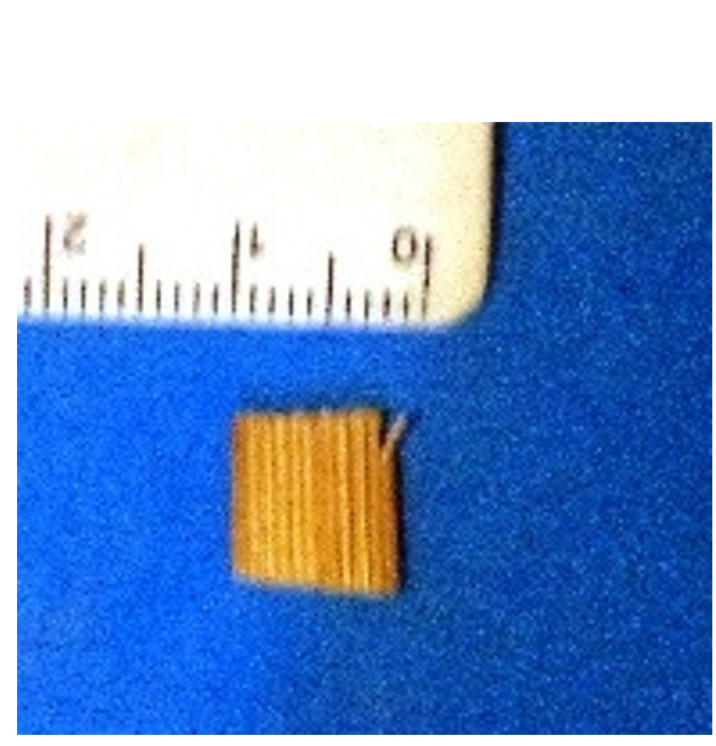

(a)

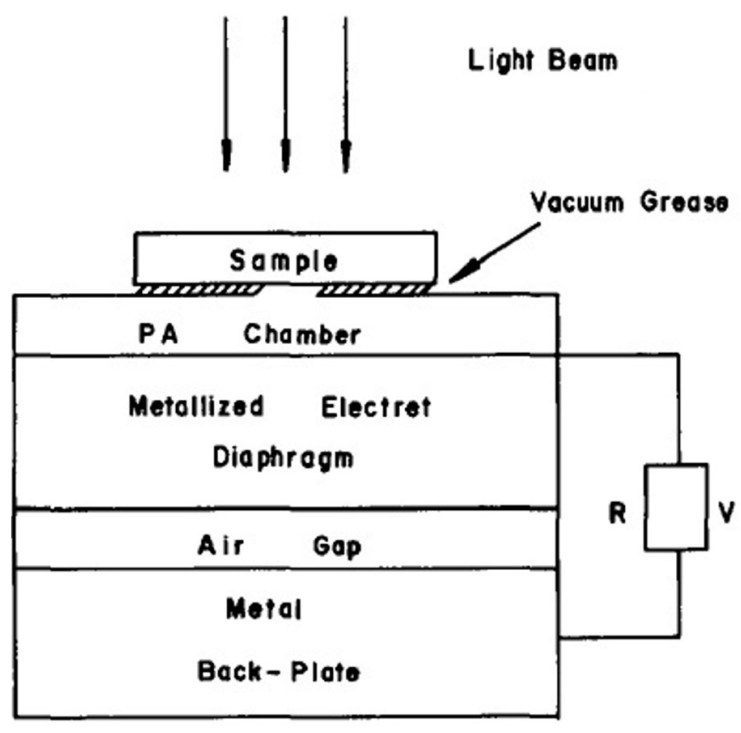

(b)

Figure 4. Photoacoustic sample (a) and schematic of the open cell for the thermal measurement (b).

Moreover, the specific heat capacity is determined by considering the following equations ${ }^{38}$ :

$$
\begin{aligned}
& \Delta \mathrm{T}=\left(\frac{\mathrm{I}_{\mathrm{o}} \tau}{\ell_{\mathrm{s}} \rho \mathrm{c}_{\mathrm{p}}}\right)\left(1-\mathrm{e}^{-\mathrm{t} / \tau)}\right. \\
& \tau=\ell_{\mathrm{s}} \rho \mathrm{c}_{\mathrm{p}}(2 \mathrm{H}) \\
& \mathrm{H}=4 \sigma \mathrm{T}_{\mathrm{o}}{ }^{3}
\end{aligned}
$$

where $\mathbf{I}_{\mathbf{0}}$ is the laser incident intensity on the sample and $\tau$ is known as the "temperature rise time", $\mathbf{H}$ is called the transfer coefficient of radiated heat and consists of the Stefan-Boltzmann constant, $\sigma$, and the ambient temperature $\mathbf{T}_{\mathbf{0}}$. Therefore, using a relatively simple but precise experiment, Figure 4b, it is possible to obtain three important thermal properties by mathematical adjustment of photoacoustic data. 


\section{Results and Discussion}

Figure 5 shows the typical phase data of the photoacoustic signal variation with its frequency $\mathbf{f}$. It is important to remember that the phase is the difference between the generated signal and the detected one. The frequency $\mathbf{f}$, used as the independent variable in Figure 5, is the modulation frequency of the laser. In this figure, the black dots represent the experimental data while the continuous line corresponds to the best mathematical fit, which represents the trajectory of the experimental points. Considering that the thickness of each sample is $\boldsymbol{\ell}_{\mathbf{s}}=0.35 \mathrm{~mm}$, then the thermal diffusivity, based on Equation 3, was determined as:

$\alpha_{\mathrm{s}}=(0.82 \pm 0.05) \times 10^{-6} \mathrm{~m}^{2} / \mathrm{s}$

By taking into account the evolution with the time of the banana fiber thermocaoustic response, when laser illumination is turned off, experimental curves were constructed as

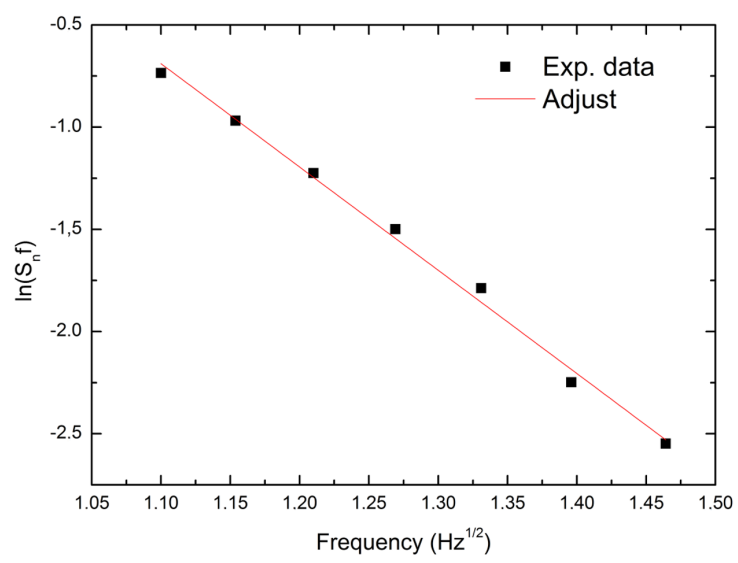

Figure 5. Phase variation of the photoacoustic signal with frequency f for the banana fiber.

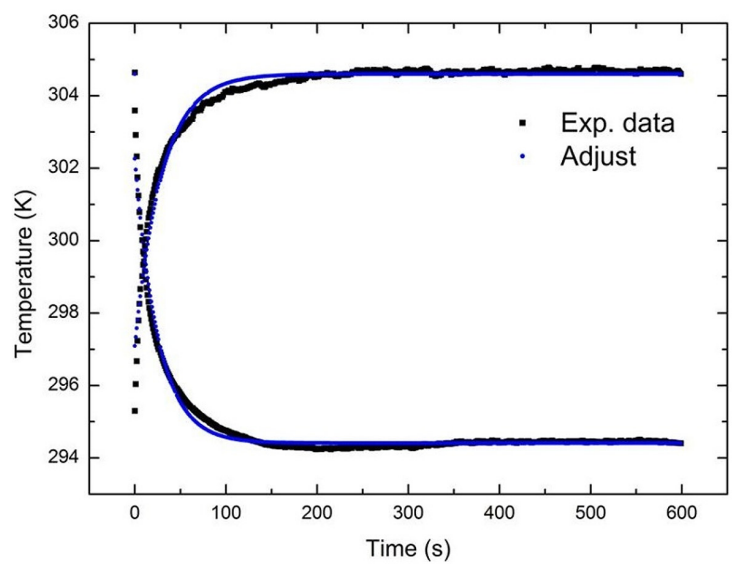

Figure 6. Temperature evolution with time on the back of the sample surface after switching off the illumination.

\section{References}

1. Agarwal BD, Broutman LJ and Chandraskekhara K. Analysis and performance of fiber composites. 3rd ed. Hoboken: Wiley; 2006. illustrated in Figure 6. In this figure, black dots correspond to the experimentally obtained data. Moreover, the continuous line represents the best mathematical fit curve for the trajectory of the experimental dots. This continuous line was calculated considering Equation 4-6. Thus, by taking into account Equation 4-6 as well as the density of banana fiber as $1500 \mathrm{~kg} / \mathrm{m}^{3}$ and using the $\tau$ value as an adjustable parameter on the curve of Figure 6, the value of the specific heat capacity of banana fiber was obtained as:

$\rho \mathbf{c}_{\mathbf{p}}=(0.67 \pm 0.09) \times 10^{6} \mathrm{~J} / \mathrm{K} \cdot \mathrm{m}^{3}$

To complete this characterization, the thermal conductivity of banana fiber was obtained by means of the values of thermal diffusivity, Equation 7, and the specific heat capacity, Equation 8, together in Equation 1 as:

$\mathbf{k}=(0.55 \pm 0.11) \mathrm{W} / \mathrm{m} \cdot \mathrm{K}$

This value is comparable to polymeric materials values ${ }^{39}$. Although the results obtained in this study are preliminary and consider only the average of three replicates, the value of thermal conductivity in Equation 9 indicates that the banana fiber has characteristics of a good thermal insulator. In principle, the banana fiber for its mechanical and thermal properties ${ }^{22-33}$ could be used as an environmentally correct thermal insulator in substitution for conventional synthetic ones. This is already occurring, as shown in Figure 2.

\section{Conclusions}

- Using the photoacoustic and photothermal fundamentals, by means of the open photoacoustic cell spectroscopy technique, basic thermal properties of banana fiber were evaluated. These properties were the thermal diffusivity, specific heat capacity and thermal conductivity.

- The thermal diffusivity was found as $\alpha_{\mathrm{s}}=0.82 \times 10^{-6} \mathrm{~m}^{2} / \mathrm{s}$ and the specific heat capacity as $\rho c_{p}=0.67 \times 10^{6} \mathrm{~J} / \mathrm{K} \cdot \mathrm{m}^{3}$ from mathematical adjustment of experimental data.

- The thermal conductivity, calculated from the product $\alpha_{\mathrm{s}} \times \rho \mathrm{c}_{\mathrm{p}}$, was obtained as $\mathbf{k}=0.55 \mathrm{~W} / \mathrm{m} . \mathrm{K}$, which indicates that the banana fiber is a promising environmentally friendly insulator and could replace conventional synthetic materials. Indeed, car parts are already being fabricated with banana fiber reinforced polymer composites.

\section{Acknowledgements}

The authors thank the support to this investigation by the Brazilian agencies: CNPq, CAPES and FAPERJ.

2. Chawla KK. Composite materials science and engineering. 3rd ed. New York: Springer; 2009.

3. Mallick PK. Fiber-reinforced composite: materials, manufacturing and design. 3rd ed. Boca Raton: CRC Press; 2008. 
4. Strong AB. Fundamentals of composites: materials, methods and applications. 2nd ed. Dearborn: Society of Manufacturing Engineers; 2008.

5. Nolan MW and Smith SA. Clinical evaluation, common diseases associated with the polymeric materials. The New York Health Journal. 2009: 1993-2012.

6. Wambua P, Ivens I and Verpoest I. Natural fibers: can they replace glass and fibre reinforced plastics? Composites Science and Technology. 2003; 63(1):1259-1264. http://dx.doi.org/10.1016/ S0266-3538(03)00096-4.

7. Joshi SV, Drzal LT, Mohanty AK and Arora S. Are natural fiber composites environmentally superior to glass fiber reinforced composites? Compos Part A. 2004; 35(3):371-376. http://dx.doi. org/10.1016/j.compositesa.2003.09.016.

8. Holbery $\mathrm{J}$ and Houston D. Natural fiber reinforced polymer composites in automotive applications. The Journal of The Minerals, Metals \& Materials Society. 2006; 58(11):80-86. http://dx.doi.org/10.1007/s11837-006-0234-2.

9. Zah R, Hischier R, Leão AL and Braun I. Curaua fibers in automobile industry: a sustainability assessment. Journal of Cleaner Production. 2007; 15(1):1032-1040. http://dx.doi. org/10.1016/j.jclepro.2006.05.036.

10. Seagrave TD. Automotive polyurethane composite parts made with natural fiber mats and honeycomb cores. Automotive SRIM Business, Composites Materials. 2008: 133-139.

11. Kalia S, Kaith BS and Kaurs I, eds. Bio-and nano-polymer composites. Berlin: Springer-Verlag; 2011.

12. Monteiro SN, Lopes FPD, Barbosa AP, Bevitori AB, Silva ILA and Costa LL. Natural lignocellulosic fibers as engineering materials: an overview. Metallurgical and Materials Transactions. A, Physical Metallurgy and Materials Science. 2011; 42(10):29632974. http://dx.doi.org/10.1007/s11661-011-0789-6.

13. Mohanty AK, Misra M and Drzal LT. Sustainable bio-composites from renewable resources: opportunities and challenges in the green materials world. Journal of Polymers and the Environment. 2002; 10(1/2):19-26. http://dx.doi.org/10.1023/A:1021013921916.

14. Netravali AN and Chabba S. Composites get greener. Materials Today. 2003; 6(4):22-29. http://dx.doi.org/10.1016/S13697021(03)00427-9.

15. Crocker J. Natural materials innovative natural composites. Natural Materials. 2008; 2-3(3):174-178. http://dx.doi. org/10.1179/175355508X373378.

16. John MJ and Thomas S. Biofibers and biocomposites. Carbohydrate Polymers. 2008; 71(3):343-364. http://dx.doi. org/10.1016/j.carbpol.2007.05.040.

17. Satyanarayana KG, Arizaga GGC and Wypych F. Biodegradable composites based on lignocellulosic fibers: an overview. Progress in Polymer Science. 2009; 34(9):982-1021. http:// dx.doi.org/10.1016/j.progpolymsci.2008.12.002.

18. Monteiro SN, Lopes FPD, Ferreira AS and Nascimento DCO. Natural fiber polymer matrix composites: cheaper, tougher and environmentally friendly. The Journal of The Minerals, Metals \& Materials Society. 2009; 61(1):17-22. http://dx.doi. org/10.1007/s11837-009-0004-z.

19. Faruk O, Bledzki AK, Fink HP and Sain M. Biocomposites reinforced with natural fibers. Progress in Polymer Science. 2012; 37(11):1555-1596. http://dx.doi.org/10.1016/j. progpolymsci.2012.04.003.

20. Thakur VK, Thakur MK and Gupta RK. Review: raw natural fibers based polymer composites. International Journal of Polymer Analysis and Characterization. 2014; 19(3):256-271. http://dx.doi.org/10.1080/1023666X.2014.880016.
21. Satyanarayana KG, Guimarães JL and Wypych F. Studies on lignocellulosic fibers of Brazil. Part I: source, production, morphology, properties and applications. Compos Part A. 2007; 38(7):1694-1709. http://dx.doi.org/10.1016/j. compositesa.2007.02.006.

22. Paul SA, Boudenne A, Ibos L, Candau Y, Joseph K and Thomas S. Effect of fiber loading and chemical treatments of thermophysical properties of banana fiber polypropylene commingled composite materials. Compos Part A. 2008; 39(9):1582-1588. http://dx.doi. org/10.1016/j.compositesa.2008.06.004.

23. Zainudin ES, Sapuan SM, Abdan K and Mohamad MTM. Thermal degradation of banana pseudo-stem filled unplastisized polyvinyl chloride composites. Materials \& Design. 2009; 30(3):557-562. http://dx.doi.org/10.1016/j.matdes.2008.05.060.

24. Costa LL, Monteiro SN, Portela TGR and Santos NSS. Characterization of natural banana fiber. In: Proceedings of the Characterization of Minerals, Metals \& Materials - TMS Conference; 2010; Seattle, USA. Warrendale: The Minerals, Metals \& Materials Society; 2010. p. 1-8.

25. Guimarães JL, Wypych F, Saul CK, Ramos LP and Satyanarayana KG. Studies of the processing and characterization of corn starch and its composites with banana and sugarcane fibers. Carbohydrate Polymers. 2010; 80(1):130-138. http://dx.doi. org/10.1016/j.carbpol.2009.11.002.

26. Ibrahim MM, Dufresne A, El-Zawawy WK and Agblevor FA. Banana fibers and microfibrile lignocellulosic reinforcement in polymer composites. Carbohydrate Polymers. 2010; 81(4):811819. http://dx.doi.org/10.1016/j.carbpol.2010.03.057.

27. Margem FM, Monteiro SN, Martins LBS, Loiola RL and Calado V. Dynamic-mechanical behavior of banana fiber reinforced epoxy matrix composites. In: Proceedings of the 67th Annual Congress of the Brazilian Association of Metallurgy and Materials; 2012; Rio de Janeiro, Brazil. São Paulo: Brazilian Association of Metallurgy, Materials and Mining; 2012. p. 1-10.

28. Margem FM, Monteiro SN, Martins LBS and Rodriguez RJS. Characterization of thermal behavior of epoxy composites reinforced with banana fiber by TGA/DTG and DSC. In: Proceedings of the Characterization of Minerals, Metals \& Materials - TMS Conference; 2012; Orlando, USA. Hoboken: John Wiley \& Sons; 2012. p. 1-8.

29. Margem FM, Martins LBS, Rosa NCG and Monteiro SN. Thermal behavior of banana fibers. In: Characterization of minerals, metals \& materials 2012. Hoboken: John Wiley \& Sons; 2012. p. 381-386.

30. Monteiro SN, Margem FM, Assis FS, Loiola RL and Margem JI. Flexural mechanical characterization of polyester composites reinforced with continuous banana fibers. In: Characterization of minerals, metals \& materials 2013. Hoboken, NJ, USA: John Wiley \& Sons; 2013. p. 175-179.

31. Monteiro SN, Margem FM, Loiola RL, Assis FS and Oliveira MP. Characterization of banana fibers functional groups by infrared spectroscopy. Materials Science Forum. 2014; 775776:250-254. http://dx.doi.org/10.4028/www.scientific.net/ MSF.775-776.250.

32. Assis FS, Monteiro SN, Margem FM and Loiola RL. Charpy toughness behavior of continuous banana fiber reinforced epoxy matrix composites. In: Characterization of minerals, metals \& materials 2014. Hoboken: John Wiley \& Sons; 2014. p. 499-506.

33. Monteiro SN, Margem FM, Assis FS, Loiola RL and Oliveira MP. Izod impact tests in polyester matrix composites reinforced with banana fibers. Materials Science Forum. 2014; 775776:261-265. http://dx.doi.org/10.4028/www.scientific.net/ MSF.775-776.261. 
34. Rosencwaig A and Gersho A. Theory of the photoacoustic effect with solids. Journal of Applied Physics. 1976; 47(1):64-69. http://dx.doi.org/10.1063/1.322296.

35. Almond D and Patel P. Photoacoustic and photothermal science and techniques. London: Chapman and Hall; 1996.

36. Vargas H and Miranda LCM. Photoacoustic and related photothermal techniques. Physics Reports. 1988; 161(2):43101. http://dx.doi.org/10.1016/0370-1573(88)90100-7.

37. Marquezini MV, Cella N, Mansanares AM, Vargas H and Miranda LCM. Open photoacoustic cell spectroscopy. Measurement
Science \& Technology. 1991; 2(4):396-401. http://dx.doi. org/10.1088/0957-0233/2/4/020.

38. Hatta I. Heat capacity measurements by means of thermal relaxation method in medium temperature range. The Review of Scientific Instruments. 1979; 50(3):292-295. http://dx.doi. org/10.1063/1.1135818. PMid:18699494.

39. Callister WD Jr and Rethwisch DG. Materials science and engineering: an introduction. 8th ed. New York: John Wiley \& Sons; 2010. 